\section{Development of pGreen-derived GFP Binary Vectors for Citrus Transformation}

\author{
Chunxian Chen, Qifa Zheng ${ }^{1}$, Xu Xiang ${ }^{2}$, Jaya R. Soneji, Shu Huang, \\ Young A Choi, Madhugiri Nageswara Rao, and Fred G. Gmitter, Jr. ${ }^{3}$ \\ University of Florida, Institute of Food and Agricultural Sciences, Citrus \\ Research and Education Center, 700 Experiment Station Road, Lake Alfred, \\ FL 33850
}

Additional index words. Agrobacterium-mediated transformation, green fluorescent protein, transformation efficiency

\begin{abstract}
Eight new green fluorescent protein (GFP) binary vectors were developed by inserting $g f p$ reporter gene cassettes into pGreen vectors. We chose one of them, pG52KF, with the $n p t I I$ selection and $g f p$ reporter gene and one recombinant construct, pG52KFp, for a preliminary evaluation in citrus using Agrobacterium-mediated transformation. High-transformation efficiency was observed, whereas green fluorescence greatly facilitated the early in vivo screening and categorizing of the transformants. These pGreen-derived GFP binary vectors, freely available on request, provide more and flexible options for genetic transformation in citrus and other woody plants.
\end{abstract}

Different serials of binary vectors such as pCAMBIA, pGA, pBIN, pGreen with regular insert capability, and BiBACs, pYLTACs with large insert capability have been reported for Agrobacterium-mediated transformation (AMT) of various plant species (Hellens et al., 2000b; Shibata and Liu 2000). Most of these binary vectors have $n p t$ II (neomycin phosphotransferase for resistance to kanamycin) as a selection gene and uidA ( $\beta$-glucuronidase for GUS assay) as a reporter gene. They allow early selection by kanamycin and later verification of transformed plants by GUS assay. The GUS assay requires a part of the plantlet to be removed for X-Gluc (5-bromo-4-chloro-3-indolyl- $\beta$ D-glycopyranoside) staining. This will obviously result in damage to or removal of the plantlet if an early stage of screening is required. Since the green fluorescent protein (GFP) gene $(g f p)$ was cloned and used as

\footnotetext{
Received for publication 12 Apr. 2006. Accepted for publication 22 July 2006

We thank Dr. Mullineaux for providing pGreen vectors and other plasmids harboring $g f p$ cassettes, Dr. Vladimir Orbovic for his help in use of fluorescent microscope, and Marjorie Wendell, Misty Holt, Becky Clarke, and Ling Wang for their technical assistance.

This research was supported in part under Project No. 0110-03I of the Florida Citrus Production Research Advisory Council, Peter McClure, Chairman, and by a grant from USDA-CSREES-NCRI 2002-34399-12765.

${ }^{1}$ Current address: Agriculture and Agri-Food Canada, Kentville Research Center, 32 Main Street, Kentville, Nova Scotia, B4N 1J5, Canada.

${ }^{2}$ Current address: Guangdong Academy of Agricultural Science, Institute of Fruit Tree Research, Guangzhou, Guangdong 510640, China.

${ }^{3}$ To whom reprint requests should be addressed; e-mail fgmitter@ufl.edu.
}

a visual marker for gene expression study (Chalfie et al., 1994), it has been applied in many organisms, including plants (Haseloff and Amos 1995; Haseloff et al., 1997). Expressed green fluorescent protein allows early detection and recovery of transgenic shoots without any damage to plantlets; thus, escape shoots, which were frequently observed in AMT (Domínguez et al., 2004; Peña et al., 1995), can be visually distinguished and categorized shortly after regeneration. One GFP binary vector, pBin19-sgfp (Chiu et al., 1996), was evaluated in citrus, indicating the advantage of GFP in the early and rapid in vivo screening of transgenic shoots (Ghorbel et al., 1999). Another nonbinary GFP vector was also used in citrus protoplast transformation (Fleming et al., 2000). These vectors usually are developed for specific use. Generally, it is very time-consuming to modify them to develop new constructs for other applications.

The pGreen is considered to be a new concept binary $\mathrm{Ti}$ vector (Hellens et al., 2000a). High-transformation efficiencies have been demonstrated in tomato and rice using some original pGreen vectors (Hellens et al., 2000a; Vain et al., 2003). The pGreen consists of a plasmid backbone plus a BglIIflanked T-DNA region containing two unique blunt restriction sites, HpaI and StuI, located internally to the left and right border sequences (LB and RB), respectively, which facilitate the cloning of any blunt selection and reporter gene cassettes. Two BglII sites are useful in cloning and posttransformation analysis. These special features allow new binary vectors to be developed optimally and quickly to meet user's different demands. Moreover, pGreen contains 18 unique cloning restriction sites within the pBlueScript polylinker maximizing the options to clone an alien gene for construct development.
Compared with other binary vectors, the size of the vector is small because the origin of the replication element required by Agrobacterium is in a helper plasmid, pSoup, thus making the manipulation relatively easy.

In this article, we report the development of eight new pGreen-derived GFP vectors and preliminary studies to evaluate one of the vectors using citrus Agrobacterium-mediated transformation.

\section{Materials and Methods}

pGreen vectors and green fluorescent protein cassettes. Three pGreen vectors, pGreenII0000 and its two derivatives, pGreen0029 and pGreen0179, and two plasmids harboring 35S-GFP and nos-GFP cassettes (the $g f p$ gene under $35 \mathrm{~S}-\mathrm{CaMV}$ and nos promoter, respectively) were provided by Dr. Phil Mullineaux's laboratory (Hellens et al., 2000a). The pGreenII0000 has no selection or reporter gene in the T-DNA portion. The pGreen0029 and pGreen0179 already had the nos-Kan (+) and 35S-Hyg (+) cassette cloned into the HpaI site within the T-DNA LB region, respectively. To avoid confusion, all shorts or abbreviations used in this article such as "Kan," "Hyg," GUS, GFP, and so on, literally represent and equally refer to the corresponding genes or functional elements. For example, "Kan" and "Hyg" represent the genes, the nptII and hpt (hygromycin phosphotransferase), which provide resistances to kanamycin and hygromycin, respectively. The $g f p$ used here originated from the jellyfish Aequorea victoria but was modified (Haseloff et al., 1997). A motif encoding a transit peptide has been attached to drive the GFP to endoplasmic reticulum (ER) where it can be stably accumulated, and codons also modified to favor recognition by, and expression in, plant genomes that can enhance fluorescence.

Ligation and digestion. An EcoRV fragment containing the $35 \mathrm{~S}-\mathrm{GFP}$ or nos-GFP cassette was recovered and inserted into the $S t u I$ site in a pGreen vector to develop new GFP vectors. One-step restriction/ligation reaction was carried out in $20 \mu \mathrm{L}$ containing $20 \mathrm{ng}$ of uncut or $S t u \mathrm{I}$-digested (without heat inactivation of the enzyme) pGreen DNA, 60 ng purified $E c o$ RV fragment, $2 \mu \mathrm{L} 10 \times$ ligation buffer, $10 \mathrm{U} S t u \mathrm{I}, 10 \mathrm{U}$ T4 DNA ligase (Biolabs, Beverly, Mass.), and $\mathrm{ddH}_{2} \mathrm{O}$ to $20 \mu \mathrm{L}$. Such one-step reaction can be performed only when the inserted fragment does not have the StuI site. The pGreen plasmids and GFP cassettes and their ligation combinations are listed in Table 1. After ligation, $5 \mu \mathrm{L}$ was mixed with $100 \mu \mathrm{L}$ JM109 competent cells for heat shock transformation (Promega, Madison, Wis.). Twelve clones from each transformation were randomly selected and cultured for plasmid minipreparation. Inserts and insert directions in recombinant plasmids were determined by $B g l \mathrm{II}$ digestion and $B g l \mathrm{II} / B s t \mathrm{BI}$ double digestion (the $B s t \mathrm{BI}$ site was present only in the $g f p$ gene but not in any other part of vector), respectively. One GFP vector, pG52KF, 
and one construct, pG52KFp, containing a trifoliate orange (Poncirus trifoliata L. Raf.) -specific SpeI fragment, were individually cotransformed with the helper plasmid, pSOUP, into Agrobacterium tumefaciens strain AGL1 competent cells by electroporation and used for a preliminary evaluation in citrus.

Agrobacterium-mediated transformation. Epicotyl segments cut from 4-week-old etiolated seedlings of grapefruit (Citrus paradisi Macf. cv. Duncan) were used as explants in this preliminary evaluation. The transformation and regeneration procedure was as described by $\mathrm{Yu}$ et al. (2002).

Fluorescence observation and polymerase chain reaction verification. The gfp expression was observed and photographed under a fluorescent microscope Zeiss SV6 4 to 6 weeks after initial selection culture (Ghorbel et al., 1999). Regenerated shoots were cut off from 6-week explants on the selection medium and micrografted onto Carrizo rootstocks. Grafted plantlets were grown on a filter paper bridge in culture tubes containing liquid MS medium for 4 weeks before transplanting into autoclaved soil ( $\mathrm{Yu}$ et al., 2002). After 4 weeks in soil, a leaf disc of $0.5-\mathrm{cm}$ diameter was punched from each regenerated plant, wiped with $75 \%$ ethanol, and immediately used for DNA extraction using the REDExtract-N-Amp plant PCR kit (Sigma, St. Louis, Mo.). PCR primers from $n p t I I$ and $g f p$ (Operon Technologies, Huntsville, Ala.) were used to verify the putative transgenic grafted plants. The $n p t I I$ primers were 5' - TCG GCT ATG ACT GGG CAC AAC AGA-3' (forward) and 5' -AAG AAG GCG ATA GAA GGC GAT GCG-3' (reverse). The $g f p$ primers were $5^{\prime}-\mathrm{TGC}$ CTG AGG GAT CTG TGC AGG-3' (forward) and 5'-TGC CAT GTG TAA TCC CAG CAG-3' (reverse). The expected sizes of PCR products would be $722 \mathrm{bp}$ and $436 \mathrm{bp}$, respectively. Standard PCR was performed using an initial denaturation of $94{ }^{\circ} \mathrm{C}$ for $3 \mathrm{~min}$ followed by 35 cycles of $93{ }^{\circ} \mathrm{C}$ for $30 \mathrm{~s}$, $55{ }^{\circ} \mathrm{C}$ for $90 \mathrm{~s}, 72{ }^{\circ} \mathrm{C}$ for $90 \mathrm{~s}$, and a final extension of $72{ }^{\circ} \mathrm{C}$ for $10 \mathrm{~min}$. PCR products were resolved on $1.5 \%$ agarose gel and stained in $0.5 \mu \mathrm{g} / \mathrm{mL}$ ethidium bromide.

Transformation efficiency. The number of $g f p$ - and nptII-amplified plantlets divided by the total number of cocultured segments was used as transformation efficiency in percentage form.

\section{Results and Discussion}

Development and verification of $p$ Greenderived binary Ti vectors. Each ligation of nos-GFP or $35 \mathrm{~S}-\mathrm{GFP}$ cassette into a pGreen vector resulted in two vectors with a GFP cassette in different inserting directions. The cassette on the vector with the same direction as $L a c \mathrm{Z}$ was marked with a plus sign $(+)$, whereas that with the opposite direction was marked with a minus sign (-). Of the first randomly picked 12 clones from each ligation, five from pGreenII0000 and 35S-GFP (1+ and 4-), five from pGreenII0000 and nos-
Table 1. Eight new green fluorescent protein vectors derived from three pGreen plasmids.

\begin{tabular}{|c|c|c|c|c|c|c|}
\hline No Vector Name & Size & $\begin{array}{c}\text { LB } \\
\text { Cassette }\end{array}$ & $\begin{array}{c}\text { RB } \\
\text { Cassette }\end{array}$ & $\begin{array}{c}\text { T-DNA Portion } \\
\text { Diagram }^{\mathrm{y}}\end{array}$ & $B g l I^{\mathrm{x}}$ & $B g l \mathrm{II} / B s t \mathrm{BI}^{\mathrm{x}}$ \\
\hline 1 pGreenII0000 & 3304 & & & & 809 & 809 \\
\hline $2 \mathrm{pG} 25 \mathrm{~F}$ & 4617 & & $n o s-\mathrm{GFP}(+)$ & & 2122 & 1138,984 \\
\hline 3 pG26F & 4617 & & nos-GFP (-) & & 2122 & 1685,437 \\
\hline $4 \mathrm{pG} 27 \mathrm{~F}$ & 4690 & & 35S-GFP (+) & & 2195 & 1087,1108 \\
\hline 5 pG28F & 4690 & & 35S-GFP (-) & & 2195 & 1809,386 \\
\hline 6 pGreen0029 & 4704 & $o s-\operatorname{Kan}(+)$ & & & 2209 & 2209 \\
\hline $7 \mathrm{pG} 52 \mathrm{KF}$ & 6090 & $o s-\operatorname{Kan}(+)$ & $35 \mathrm{~S}-\mathrm{GFP}(+)$ & & 3595 & 2487,1108 \\
\hline 8 pG53KF & 6090 & $o s-\operatorname{Kan}(+)$ & 35S-GFP (- & & 3595 & 3209,386 \\
\hline 9 pGreen0179 & 5138 & $5 \mathrm{~S}-\mathrm{Hyg}(+)$ & & & 2643 & 2643 \\
\hline 10 pG200HF & 6451 & $5 \mathrm{~S}-\mathrm{Hyg}(+)$ & $n o s-G F P(+)$ & & 3956 & 2972,984 \\
\hline $11 \mathrm{pG} 201 \mathrm{HF}$ & 645 & C U Jus (1) & $-)$ & & 3956 & 3519,437 \\
\hline
\end{tabular}

zpG25F, pG26F, pG27F, and pG28F (nos. 2, 3, 4, and 5) derived from pGreenII0000 (1), pG52KF and pG53KF (7 and 8) from pGreen0029 (6), and pG200HF and pG201HF (10 and 11) from pGreen0179 (9). All listed here for comparison.

${ }^{\mathrm{y}}$ The diagrams representing the genes or elements in the T-DNA portion are as follows: long arrows filled with narrow horizontal lines (LacZ), spheres ( $g f p)$, plaids ( $n p t \mathrm{II})$, and solid diamonds ( $h p t)$; short arrows (promoter) and rectangles (terminator) in grey (nos) and black (35S); short rectangles in white (LB and $\mathrm{RB})$ at the ends.

${ }^{\mathrm{x}}$ The expected sizes of $B g l \mathrm{II}$ and $B g l \mathrm{II} / B s t \mathrm{BI}$ restriction fragments from the T-DNA portion of each vector were deduced. Common 2495 bp plasmid backbone fragment, generated by both digestions, was not listed here. The restriction patterns are seen in Figures 1A and B, respectively.
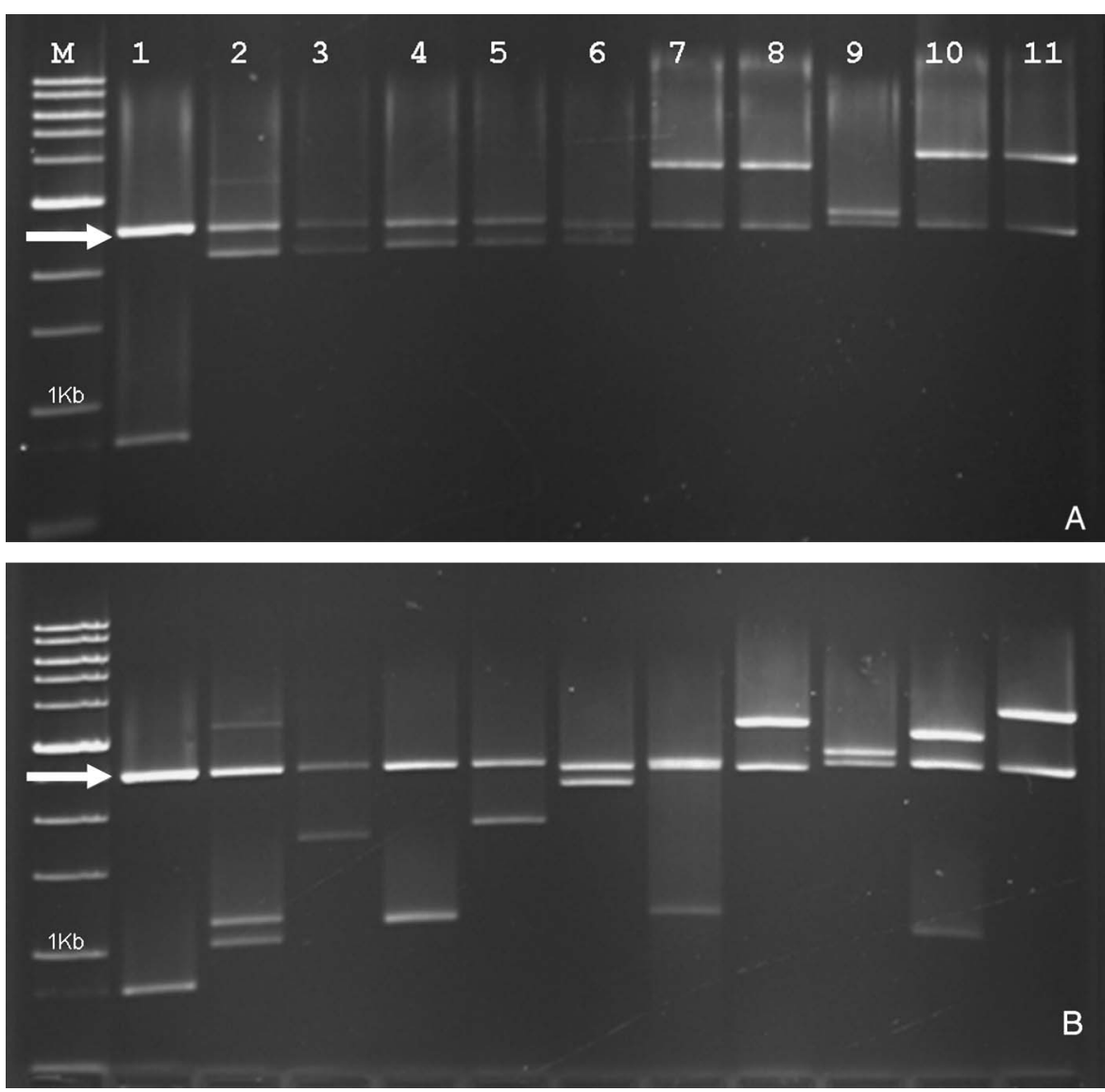

Fig. 1. The $B g l \mathrm{II}(\mathbf{A})$ and $B g l \mathrm{II} / B s t \mathrm{BI}$ (B) restriction patterns of eight new green fluorescent protein vectors (lanes 2, 3, 4, 5, 7, 8, 10, and 11) and three original pGreens (lanes 1, 6, and 9, same in $\mathbf{A}$ and $\mathbf{B}$ because of no BstBI site). The lane numbers here matched those in column 1 in Table 1 . These BglII/Bst BI fragments expected in Table 1, $437 \mathrm{bp}$ in lanes 3 and 11, and $386 \mathrm{bp}$ in lanes 5 and 8, were not presented because of small size, and $1087 \mathrm{bp}$ and $1108 \mathrm{bp}$ in lane 4 and $2487 \mathrm{bp}$ and 2495 bp in lane 7 were not separated because of irresolvable size difference. Both white arrows indicated the common $2495 \mathrm{bp}$ plasmid backbone fragment. M: 1-kb ladder (Cat. No. N3232S, Biolabs, Beverly, Mass.) in which 1 kb is labeled above the corresponding band. 

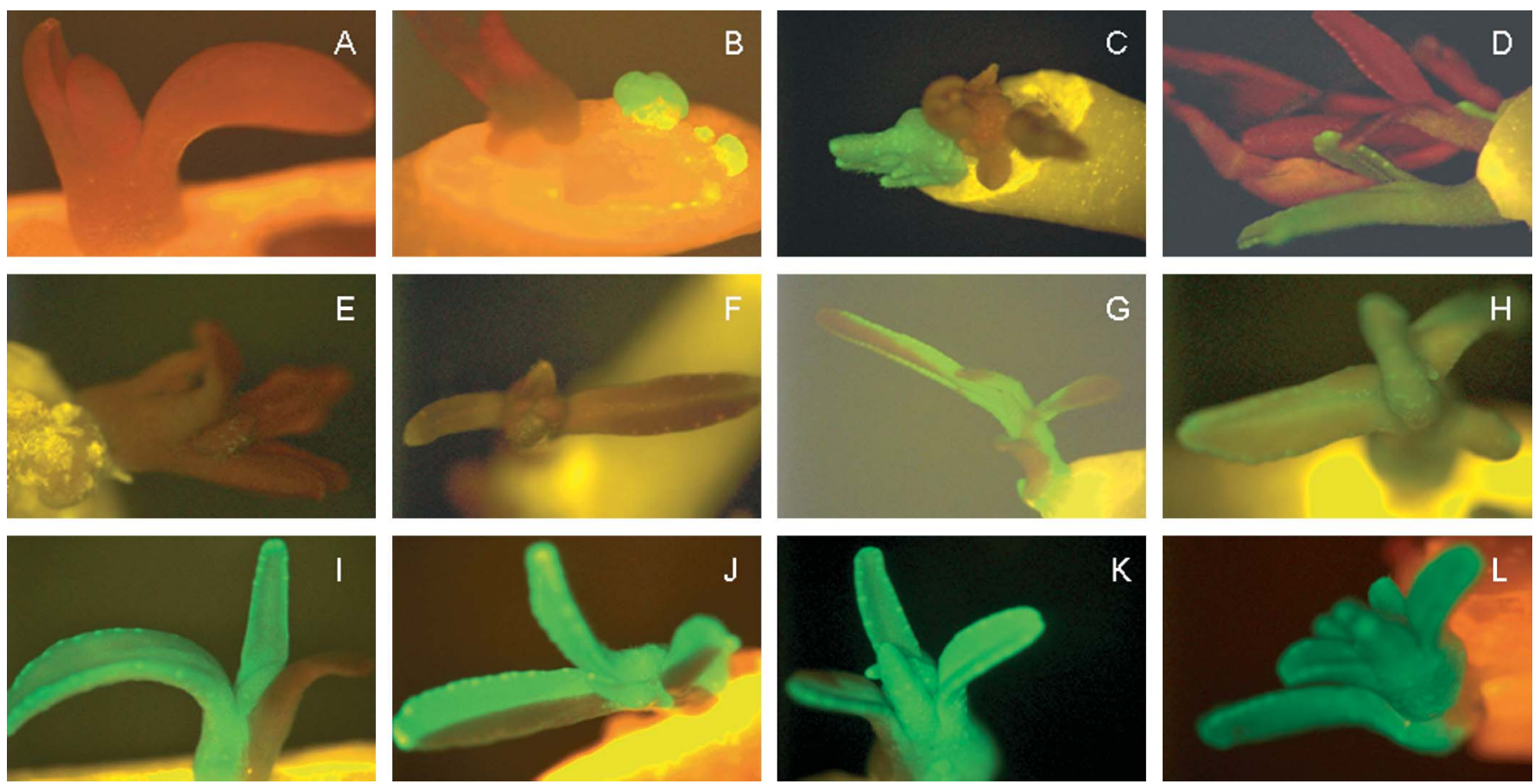

Fig. 2. Regenerated shoots with and without $g f p$ expression photographed under a fluorescent microscope Zeiss SV6 with an HBO100ARC mercury lamp. (A) Nontransformed control with red fluorescence; $(\mathbf{B}-\mathbf{L})$ transformed shoots from the individual explants with different patterns and levels of green fluorescence, co-occurring with nontransformed shoots at the same explants $(\mathbf{B}, \mathbf{C}$, and $\mathbf{D})$, weak $(\mathbf{E}$ and $\mathbf{F})$, partial $(\mathbf{G}$ and $\mathbf{H})$, strong with localized reduction or absence $(\mathbf{I}, \mathbf{J}$, and $\mathbf{K})$, or very strong (L).

GFP (1+ and 4-), six from pGreen0029 and 35 S-GFP (3+ and 3-), and two from pGreen0179 and nos-GFP (only 2-) contained the expected GFP inserts. The clone numbers with different insert directions were listed behind each combination of ligation. To acquire the $(+)$ nos-GFP from the ligation of pGreen0179 and nos-GFP, 36 more clones were selected and three nos-GFP clones were identified, one in the $(+)$ and two in the $(-)$ direction. Eight new GFP binary Ti vectors, together with the original pGreenII0000, pGreen0029, and pGreen0179, are listed in Table 1, in which the sizes of vectors were deduced from the known DNA sequences; so were those of the expected $B g l \mathrm{II}$ and $B g l \mathrm{II} /$ $B s t \mathrm{BI}$ restriction fragments. The T-DNA portions of the plasmids were released in full from the plasmid backbone by BglII restriction (Fig. 1A) and cut into two fragments of direction-related sizes by $B g l \mathrm{II} / B s t \mathrm{BI}$ restriction (Fig. 1B) to determine the insert and insert direction. With GFP cassette inserted in opposite directions, the paired vectors, from the T-DNA portion of which different sizes (deduced in Table 1) of two BglII/Bst BI fragments (Fig. 1B) were generated, were 2 and 3, 4 and 5, 7 and 8 , and 10 and 11 . These vectors can be used in different applications, including protoplast transformation or AMT. Also, vectors with different selection and/or reporter genes can be used together to transfer different target genes into the same plantlets through simultaneous selection by different antibiotics or detection of all expressed reporters (Soneji et al., 2006).

gfp expression and polymerase chain reaction detection in putative transgenic shoots. Four-week explants with new shoots
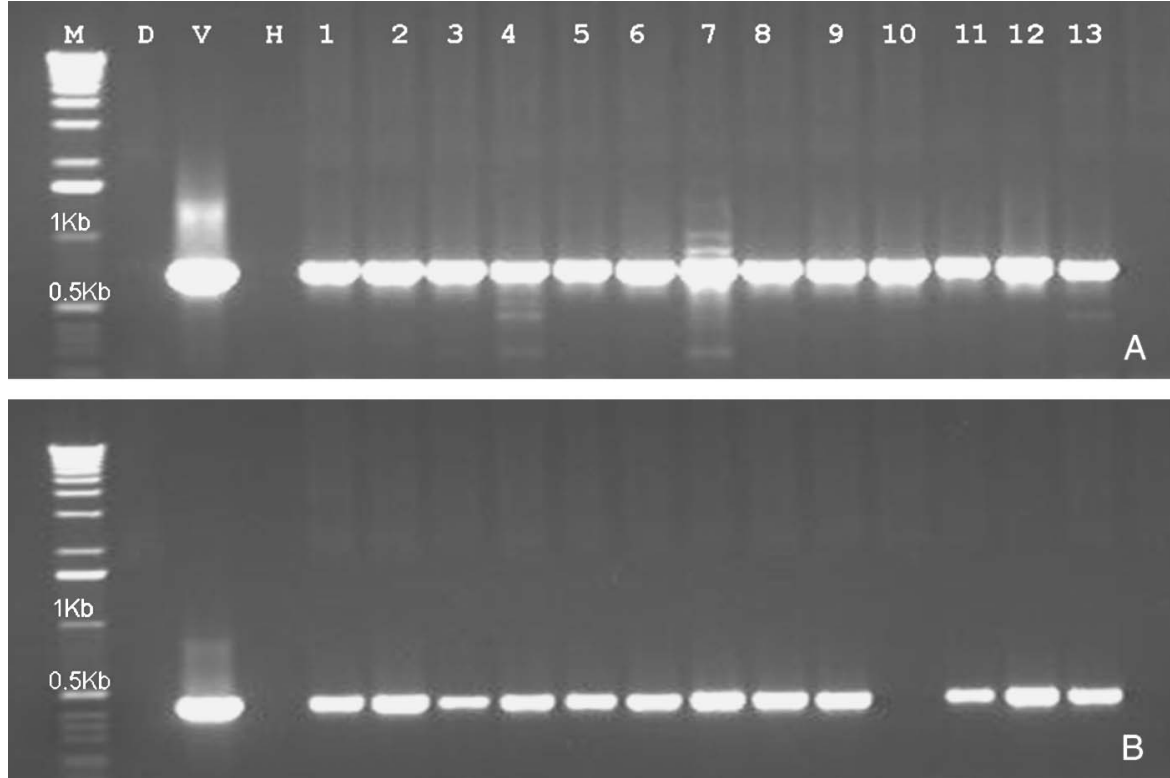

Fig. 3. Polymerase chain reaction detection of $n p t I I(\mathbf{A})$ and $g f p(\mathbf{B})$ genes in regenerated plantlets with (17) or without (8-13) fluorescence observed. Both sizes of $n p t I I$ and $g f p$ amplicons were as expected, $722 \mathrm{bp}$ and $436 \mathrm{bp}$, respectively. The plantlets $1-5$ and $8-10$ were from the pG52KFp and the remaining from the empty pG52KF vector. The $g f p$ was not detected in lane 10 from a sample that did not show fluorescence. M: 1-kb ladder (Cat. No. 15615-016, Invitrogen, Carlsbad, Calif.) in which $1 \mathrm{~kb}$ and $0.5 \mathrm{~kb}$ are labeled above the corresponding bands; D: Duncan; V: vector pG52KF; $\mathrm{H}: \mathrm{H}_{2} \mathrm{O}$.

were chosen to observe the $g f p$ expression under a fluorescent microscope. A total of 12 and 13 shoots were regenerated from 142 pG52KF and 501 pG52KFp cocultured segments, and green fluorescence was observed on six and five of them, respectively, at different levels and patterns (Fig. 2). PCR detection using the leaves of micrografted plantlets revealed that all 11 green fluores- cent plantlets harbored both $n p t I I$ and $g f p$ genes (Fig. 3). Observed green fluorescence and amplified gene fragments strongly suggested that these plantlets were transgenic. Both genes were also amplified from 10 shoots (five from the vector and five from pG52KFp) without green fluorescence. The transformation efficiency of $\mathrm{pG} 52 \mathrm{KF}$ was found to be $7.75 \%(11 / 142 * 100 \%)$, whereas 
that of pG52KFp was $2.00 \%(10 / 501 * 100 \%)$. The insert size appeared as a factor related to transformation efficiency. Failure to express the $g f p$ likely resulted from silencing or deletion of the integrated alien gene, which usually is observed in transformed plants (Domínguez et al., 2004), or splicing of an internal intron of $g f p$ (Haseloff and Amos 1995). Of the remaining four plantlets without fluorescence, three had only $n p t \mathrm{II}$ amplified (one of them in lane 10 in Fig. 3), and one had neither of them detected. They might be so-called escape shoots (Domínguez et al., 2004; Peña et al., 1995). There was no plantlet with only the $g f p$ amplified. The new shoots with no and strong fluorescence were observed simultaneously to be regenerated from the same explants (Fig. 2B-D). Different levels and localization of $g f p$ expression was found to be common in transgenic plantlets (Domínguez et al., 2004; Ghorbel et al., 1999). It was unclear if the phenomenon resulted from possible chimerism or the nature of the integrated gene expression.

Concern about fluorescence observation and PCR detection was often raised because of the persistence of Agrobacterium, alive or dead, on citrus and other plant explants, which might result in occasional cases of false-positive transgenic plants (Domínguez et al., 2004). It also occurred on some tobacco regenerants, although Agrobacterium was mostly detected on regenerated roots rather than on regenerated leaves (Matzk et al., 1996). In the present experiment, sampling from the leaves of the plantlets in soil can basically eliminate the possibility of such "contamination" because they came from the micrografting of only the apical part of the regenerated shoots. Moreover, citrus species are not natural hosts of $A$. tumefaciens, which minimize the survival chance in air and soil (Domínguez et al., 2004). The gene fragment from Poncirus was also amplified from the $g f p$-expressed plantlets from pG52KFp (data not shown). The visual green fluorescence in these fragile transformants will directly ensure the early identification in vivo and categorization of transgenic plants without any damage. This preliminary evaluation and resulting transformation efficiency suggested the pG52KF may be a promising vector for citrus transformation; it is being continuously used in our laboratory as well as being evaluated on apple AMT (Zhu, personal communication, 27 Jan. 2006). These new pGreen-derived GFP vectors, with all special features from pGreen and added $g f p$ reporter gene for in vivo screening of transformants, will allow more and flexible options for transformation and genetic engineering in citrus and many other recalcitrant horticultural crops. All these vectors will be freely distributed on request to cxchen@ufl.edu or fgmitter@ufl.edu.

\section{Literature Cited}

Chalfie, M., Y. Tu, G. Euskirchen, W.W. Ward, and D.C. Prasher. 1994. Green fluorescent protein as a marker for gene expression. Science 263:663-664.

Chiu, W., Y. Niwa, W. Zeng, and T. Hirana. 1996. Engineering GFP as a vital reporter in plants. Curr. Biol. 6:325-330.

Domínguez, A., M. Cervera, R.M. Pérez, J. Romero, C. Fagoaga, J. Cubero, M.M. López, J.A. Juárez, L. Navarro, and L. Peña. 2004. Characterization of regenerants obtained under selective conditions after Agrobacteriummediated transformation of citrus explants reveals production of silenced and chimeric plants at unexpected high frequencies. Mol. Breed. 14:171-183.

Fleming, G.H., O. Olivares, S.F. Del-Bosco, and J.W. Grosser. 2000. An alternative method for the genetic transformation of sweet orange. In Vitro Cell. Dev. Biol. Plant 36:450-455.
Ghorbel, R., J. Juarez, L. Navarro, and L. Peña. 1999. Green fluorescent protein as a screenable marker to increase the efficiency of generating transgenic woody fruit plants. Theor. Appl. Genet. 99:350-358.

Haseloff, J. and B. Amos. 1995. GFP in plants. Trends Genet. 11:328-329.

Haseloff, J., K.R. Siemering, D.C. Prasher, and S. Hodge. 1997. Removal of a cryptic intron and subcellular localization of green fluorescent protein are required to mark transgenic Arabidopsis plants brightly. Proc. Natl. Acad. Sci. USA 94:2122-2127.

Hellens, R.P., E.A. Edwards, N.R. Leyland, S. Bean, and P.M. Mullineaux. 2000a. pGreen: a versatile and flexible binary $\mathrm{Ti}$ vector for Agrobacterium-mediated plant transformation. Plant Mol. Biol. 42:819-832.

Hellens, R.P., P.M. Mullineaux, and H. Klee. 2000b. A guide to Agrobacterium binary Ti vectors. Trends Plant Sci. 5:446-451.

Matzk, A., S. Mantell, and J. Schiemann. 1996. Localization of persisting Agrobacteria in transgenic tobacco plants. Mol. Plant Microbe Interact. 9:373-381.

Peña, L., M. Cervera, J. Juarez, C. Ortega, J.A. Piña, N. Duran-Vila, and L. Navarro. 1995. Agrobacterium-mediated transformation of sweet orange and regeneration of transgenic plants. Plant Cell Rep. 14:616-619.

Shibata, D. and Y.-G. Liu. 2000. Agrobacteriummediated plant transformation with large DNA fragments. Trends Plant Sci. 5:354-357.

Soneji, J.R., C. Chen, M. Nageswara Rao, S. Huang, Y.A. Choi, and F.G. Gmitter Jr. 2006. Agrobacterium-mediated transformation of citrus using two binary vectors. Acta Hort. (In press).

Vain, P., A.S. Afolabi, P. Worland, and J.W. Snape. 2003. Transgene behavior in populations of rice plants transformed using a new dual binary vector system: PGreen/pSoup. Theor. Appl. Genet. 107:210-217.

Yu, C., S. Huang, C. Chen, Z. Deng, P. Ling, and F.G. Gmitter Jr. 2002. Factors affecting Agrobacterium-mediated transformation and regeneration of sweet orange and citrange. Plant Cell Tissue Organ Cult. 71:147-155. 